\title{
"Who Bothers!"
}

\section{A Common Ailment in Higher Education ELT Classrooms in Nepal}

\author{
Kamal Kumar Poudel ${ }^{1} \&$ Netra Prasad Sharma ${ }^{2}$ \\ ${ }^{1}$ Tribhuvan University, Mahendra Ratna Campus, Tahachal, Kathmandu, Nepal \\ ${ }^{2}$ Netra P. Sharma, Tribhuvan University, Department of English Education, Mahendra Ratna Campus, Tahachal, \\ Kathmandu, Nepal \\ Correspondence: Kamal Kumar Poudel, Department of English Education, Tribhuvan University, Mahendra \\ Ratna Campus, Tahachal, Kathmandu, Nepal.
}

Received: May 29, 2019 Accepted: June 30, 2019 Online Published: July 1, 2019

doi: 10.5539/elt.v12n8p1 URL: https://doi.org/10.5539/elt.v12n8p1

\begin{abstract}
Critics of higher education in Nepal, even the concerned agencies, are much worried about the decreased quality resulting in low employability of higher education. The most common adjectives used by them to describe this state are 'theoretical' and/or 'impractical'. The present case study was instigated when two college students of third year Bachelor's degree majoring in English, one from Bachelor of Arts (B. A.) and the other from Bachelor of Education (B. Ed.), remarked that the excessive lecture-based classes at college were not worth attending regularly. Stemming from this problem, each of the classes was observed once to see if the students' remark would be verified. As a triangulation process, the observation was then followed by an informal post-class interaction with the faculties whose classes were observed. This article, thus, basically assesses the efficacy of the excessive lecture (EL) within the limitation of teaching English to adult learners of higher education in Nepal Considering the inefficacious nature of EL to cause learning, and the faculties' (Note 1) perceptions towards, and an over-attachment with, this method as the unique one, some alternative strategies applicable to English language teaching (ELT) classes have been recommended with the hope that they would be properly used to keep the burdened use of EL reasonably low. The article also recommends some changing roles of faculties involved in ELT in the higher education sector.
\end{abstract}

Keywords: English language teaching, higher education, faculty, excessive lecture, alternative strategies, semi-drop-out

\section{Introduction}

In Nepal, stakeholders as critics of education- from the general public and students to educationists- are often found expressing their concerns regarding the quality of education. Their worries are mostly about the way classroom teaching is conventionally carried out. The study on which this article builds is delimited to the mainstream teaching method most commonly observed in the ELT classroom in higher education which in essence finds its roots complicatedly linked with the way the college faculties were taught English as a foreign/second language at the school level. The following truncated corpus, sketching a secondary school-level ELT scenario in Nepal, comes from a three-paragraph text comprising 321 words from an article entitled, "Teaching English as a Foreign/Second Language in Nepal: Past and Present".

---teachers...still follow grammar translation method--- structure of the classroom, benches and desks --teacher centred... lecture the subject matter--- more practice to the teachers than to the students--classrooms...mostly big... difficult... to impart skills and knowledge... crowded and noisy environment--frequent and considerable use of Nepali...students hardly get exposed to English--- [in private schools] teachers speak more English... the participation of students... very low--- grammatical dissection and rote memorization--- [for students] no opportunity or encouragement to use the language--- not conducive to good teaching and learning--- despicable condition... poor physical facilities, improper teaching methods and materials. (Original source: Bista, 2011, p. 5)

The corpus depicts the methods and situation in which teaching in general and teaching English as a foreign language in particular is being operated in the majority of schools in Nepal. As regards the ELT method 
underlying this corpus, most of the traces correspond with a lecture-dominated Grammar Translation Method.

As regards classroom delivery in higher education in Nepal, Law (2012) opines that teacher's over-intervention with the learning process and the learners' over-dependence on the teacher's delivery are the major problems. As she observes, the [Nepalese] students mistakenly equate teaching with learning and they are not convinced that they can learn until the teacher stands up and lectures in front of the class. She indicates the need for fighting to change this misconception.

The phenomenon under our consideration could best be explained in alignment with the social constructivist worldview. Social constructivists view that "subjective meanings are negotiated socially and historically... are formed through interaction with others and through historical and cultural norms that operate in individuals' lives" (Creswell, 2007, p. 21). This suggests how and why the knowledge of the way we were taught affects the way we teach (Mackay, 2015). Observation also shows that, like culture, the modes and modalities of teaching are often shaped by a set of assumptions formed unconsciously by individuals as the members of the classroom during school education, and the 'dominant methodology' forms very powerful- and the most convenientknowledge and habits which the individuals transfer to the institutions of higher education later on given that they grow to be teachers in those institutions without any special attitudes and skills intentionally developed through some kind of exposure or intervention. Then it is also natural that such teaching modes and modalities as sketched in the corpus can also be found being reflected commonly in the classrooms of higher education in Nepal, including the ELT classroom, no matter what faculty-specific classroom it might be- English under the Faculty of Education (FoE), which fundamentally focuses on linguistics and language teaching, and the Faculty of Humanities $(\mathrm{FoH})$, which primarily emphasizes arts and literature.

\subsection{Context}

As a tendency, the nature of Nepalese education, both school and higher levels, becomes a matter of oral discourse even in informal gatherings and talks in Nepal. Some common descriptors employed in such discourses are 'theoretical', 'unproductive', 'leading to unemployment' 'exam-oriented' 'reciting' and the like. Once on a rather informal occasion, a somehow knowledgeable person, who was also a guardian of a student whom I (Note 2) taught English at college, brought his opinion into the fore, "We are not very satisfied with my (our) children's education today: it's [excessively] theoretical and impractical; not being applicable to their day-to-day practical needs and employability." I was really struck by his remark. The remark made me realize that it was an issue worth researching into to suggest some alternative ways to overcome the problematic situation.

After a few years, I came to know that two college students under my general supervision were reported to have stayed back in their room, thereby not attending their classes at college [regularly]. I set out to investigate their reasons for doing so, and developed a case which resulted in some further steps of investigation. This article comes as the report on the process and results of the investigation, thereafter providing some recommendations for improvement based on the results.

\section{The Essence of Teaching and Learning}

Dynamics of attitude, conception and theory- both in written literature and oral interaction- were explored by searching how people perceived and conceptualized teaching and learning. They are briefly brought into light in this section.

Learning theorists advocate that learning should come in the form of action. Let us consider:

- "The learner is not the passive victim of his environment." (Snygg, as cited in Kochhar, 1967, p. 23).

- "Knowledge is nothing but an instrument for action." (Deway, as cited in Kochhar, 1967, p. 11).

Hence, learners should not be mentally troubled in the name of teaching and learning, nor should they be experimented, rather they need to have opportunities to learn by doing.

Experts in the field maintain that students need to be independent/autonomous learners.

- " $\quad$ To learn the pupil might be weak grammar but sound pedagogy." (Kochhar, 1967, p. 11).

- "Teaching is guiding and facilitating learning, enabling the learner to learn, setting the conditions for learning." (Brown, 1994, p. 7).

Law (2012) argues that:

- It is NOT your job to tell the students everything. It is NOT your job to tell them a summary and consider your work done. It's THEIR job. Your job is to provide a forum in which they CAN get meaning, and to scaffold 
the lessons so they do it on their own. Teaching students the skills of getting meaning from a text is essential because sooner or later they will have to do it on their own. Telling them the answers is no doing them any favors. On the contrary, [if you do so] you are making them dependent and weak, and it makes for weak citizens who cannot think or articulate their arguments. (p. IV)

The teacher's role then is to empower learners to learn on their own rather than just pouring everything on them.

Similarly, most guardians in Nepal, as stated earlier, are much worried about their children's unemployment despite their higher education which, they think, is too theoretical and impractical.

As pedagogists hold that the central essence of teaching is to cause learning in learners in the true sense. Brown (1994) suggests:

- “... guiding and facilitating learning, enabling the learner to learn, setting the conditions for learning" (p.7).

Scholars/experts in andragogy argue that adult learners are mature human beings with a reasonably adequate reservoir of experience, social responsibility, ability of performance or skills and internal motivation. Referring to Knowels, Loeng (2018, pp. 4-5) points out that:

- Their [mature learners'] self-concept moves from one of being a dependent personality towards being a self-directed human being;

- They accumulate a growing reservoir of experience that becomes an increasingly rich resource for learning;

- Their readiness to learn becomes oriented increasingly towards the developmental tasks of their social roles;

- Their time perspective changes from one of postponed application of knowledge to immediacy of application, and, accordingly, their orientation towards learning shifts from one of subject-centeredness to one of performance-centeredness; and

- As a person matures, the motivation to learn is internal.

In all these senses, adults possess sources and resources of their own. What the teacher needs to do is to help them learn: interference is barely a desired teaching strategy among andros.

In harmony with andragogists' beliefs, we, the researchers, have found andros remarking:

- The teacher should understand my social status: I am not a child after all! (An M. Phil. andro talking in the canteen with his colleague during the break);

- The teacher can best utilize what we know but never lets us any opportunities. If I were... (An M. Ed. andro with his room-mate in their room).

Hence, adult learners are sensitive to their social 'faces' and sometimes much more confident than the teacher $\mathrm{him} /$ herself, and so, hope for their leading roles in the classroom.

Teachers have their own perceptions. Rahman, Babu and Ashrafuzzaman (2011) report a Bangladeshi teacher justifying his so-called question-answer method thus:

- "Question-answer means delivering the lesson ... If they listen to me attentively they can answer and if they cannot answer then I can understand that they didn't take anything from my teaching"! (p. 100).

This exemplifies that Bangladeshi teachers, like the Nepalese, tend to seek their roles under the 'jug-and-mug theory' in which the learner is regarded as an empty mug and the teacher is a full jug tipping the liquid into the mug (Rosen, 2010).

Similarly, a report submitted by the Economist Intelligence Unit (EIU, 2014) to the British Council indicates that some South Asian countries including Nepal have been facing a paradox: despite a high university enrolment, graduate employment is low there. English language skills, among other things, are the reasons why employers are struggling to find good and qualified workers. The report also points out that most university teachers in the region are not qualified enough to conduct teaching in a desired way and that they are also low paid.

On occasions, we have also found adult students reacting against classes which assume students as thoroughly attentive listeners, and so, passive leaners: "I don't like passing days listening to the same old, tedious lectures. I'd rather get some guess papers and read them just when the exam is heading close. What matters is passing anyhow. Who bothers?"

The discussion above provides us with some insights into the essence of learning and teaching in the true sense. Hence, learning is a learner development process- a form of action. It should help learners to grow to be 
independent. All that teaching needs to do is to help learning in learners- to empower them rather than impose, or interfere with what the teacher knows. As regards adult learning, teaching is meant for helping learners grow through their experience, responsibility and performance or skills. In a nutshell, teaching and learning aniticipate learner-centeredness.

\section{Methodology}

This study philosophically aligns with the interpretive paradigm which assumes that "research can never be objectively observed from the outside rather it must be observed from inside through the direct experience of the people" (Mack, 2010, p. 8). Similarly, the study is based on the qualitative method of research design in that the data and their analysis are descriptive rather than statistical.

\subsection{Participants}

In the first phase of the study, two college students (one B. A. and the other B. Ed.), both majoring in English, made the participants of the study. Information, mainly reasons and attitudes about their absence in the college, was collected informally through conversations. In the second phase, two respective college faculties (F1 who taught the B. A. students of English and F2 who taught the B. Ed. students of English) and the students were observed in the actual workplace, that is, the real classroom. In the third phase, the teachers whose teaching was observed participated in the post-class interaction.

\subsection{Approach}

The present study built on the case study approach involving both individuals and a situation in their natural context. A case study was conceived here as highly context-based interpretative research approach that "provides an account of practices that pre-exist the arrival of the researcher and continues to exist after their departure" (Miles, 2015, p. 315). The case study approach was applied to the study because it is usually thought to be helpful particularly when the researcher aims at providing an in-depth exploration and explanation of the phenomenon, issue or event under consideration.

\subsection{Design}

This study was a single 'snapshot' of generally existing actions under a given phenomenon and the individuals' views regarding the actions. More specifically, it can be characterized as the instrumental type of case study which uses a particular case, better than others, to obtain a broader appreciation of an issue or phenomenon (Crowe, Creswell, Robertson, Huby, Avery, \& Sheikh, 2011).

\subsection{Tools}

The main tools used for the study were a recording device and a diary to note down the major observations in the classrooms and the participants' views.

\subsection{Techniques and Procedures}

The techniques used in this study included informal face-to-face conversation, class observation, and post-class interaction with the faculties. When I, the principal author (Note 2), noticed that two graduate students of ELT under my general care stayed back without attending their classes I wished to investigate their reasons for doing so. This came as the first case for the study. As soon as I had completed the case study, I started collaborating with the corresponding author (Note 2) for the rest of the research process. Having been permitted by the respective college administration and the faculties, we observed two classes, one in relation to each of the students, as the second case. Thirdly, as a triangulation process, we managed a post-class informal interaction with the faculties whose classes we had observed.

\subsection{Data}

The information collected from the graduate students, the class observation records and the post-class informal interaction with the respective faculties made the primary data for this study. We used books and international journal-based research articles as the sources of secondary data.

\subsection{Validation}

The data collected at different levels of the study were validated with participant as well as methodological triangulation. Information from the students was triangulated with class observation and that from the class observation was triangulated with the post-class interaction with the faculties.

\subsection{Analysis}

We compared the results of the observation of the two classes we observed, and identified the similarities 
and differences, which made the basis for establishing the major patterns of the lesson presentations. These patterns drawn from the data served as the basis for further verification and investigation of the reasons for those teaching practices. We organized the data in the form of two cases and made meanings of the non-numerically obtained data verbally. Conceptualizing the study design as the instrumental type, we made appreciation/generalization of the results while concluding the study.

\section{Results and Interpretation}

As stated earlier, two students, one from B. A. (Mr. J.) and the other from B. Ed. (Mr. L.), both majoring in English from a college located in a geographically peripheral, if not remote, area of Nepal, were of special concern to me because their guardian had entrusted me for their general care. As a research problem, I noticed their having remained in the room without going to the classes. As a researcher, I decided to conduct a case study of the problem. Two cases were developed, analyzed and interpreted to investigate the causes of the problem. The first case was concerned with the causes of the two students' absence in the classes, which led to the observation of their classes at college as the second case, and then to a post-class interaction with the college faculties, i.e. their subject teachers, for triangulation. The results are presented in the texts below.

\section{Case for Analysis 1}

Before I was transferred to a college in Kathamandu, at which I teach now, I used to teach at one located in the eastern part of Nepal. One day an ex-neighbor of mine from the village where I was brought up came with two boys who looked like in their early twenties. As they were introduced, the boys were his brother's and sister's sons. His brother's son (Mr. J.) and his sister's son (Mr. L.) had joined B. A. and B. Ed., both majoring in English respectively in the college where I taught. In fact, he wanted that the boys lived somewhere near my residence so that I would oversee them as necessary. How could I deny him? The boys started living in a rented room not very far from my house and going to college. However, I was transferred to Kathmandu after a few months. This made it impossible for me to take a general care of the boys. Three years later, when I, along with NPS (the corresponding author) as a guest, went back home for a few weeks, it came to my notice that the boys did not attend their classes at college regularly. At the preliminary stage, I invited Mr. J to my house to tea and asked informally how their study/preparation was going on and why he had remained absent at college.

Mr. J. expressed his discontentment, "I don't like passing days listening to the same old, tedious lectures. I often feel lazy and dozy listening to the lectures for long. So, I'd rather get some guides and guess papers and read them just when the exam is heading close. What matters is passing [the examination] anyhow. Who bothers?!"

A few days later I personally visited Mr. L in his room and put forth the same inquiry as with Mr. J. Mr. J. argued, "I find going to college like killing time. When I have books in the room I can read on my own. What happens at college is not very different: the teacher just tells something about the topic, which we can read in books here. I think I can prepare better at home than at college. Who bothers anyway?"

It stands out from the case that Mr. J., being lectured to, suffers from monotony. It is natural that one feels bored, 'lazy' and even 'dozy' hearing someone regularly for an extended period of time. Similarly, Mr. L. does not find any meaning in going to college: he equates going to college with 'killing time'. If he has books at home anyway, it is meaningless for him to go to college because, if so, he can read and 'prepare better at home'. Hence, each of the boys has his own genuine reasons for not attending the classes regularly and none of them has been 'tracked-out', either. More technically speaking, both of the college students are bothered in the classroom with the over-use of the lecture method, which after Wallace (2010), can be defined as, "A system of teaching where a tutor talks to the students for an extended period of time usually between 45 minutes and one hour (p. 44)... essentially one-way interaction" (p. 45).

What Mr. J. and Mr. L. remarked really struck me. I decided that whether their classes were the way they portrayed needed verification before fully believing them. As a way forward, I decided the issue worth researching into, that is, through observation. Thus, this led to another case study for which both of us collaborated.

\section{Case for Analysis 2}

We visited the college as a guardian and researcher(s). As an extra advantage, the administration, the teaching faculties and the staff were adequately familiar with me because I had been an ex-lecturer at that very college for years. We personally consulted the assistant campus chief and made him clear about our purpose of coming to him this time. In other words, we wanted him to manage opportunities for us to observe two representative Third Year classes of English- one from B. A. and the other from B. Ed. He wholeheartedly welcomed our request and 
immediately consulted with two of the faculties about our request. He informed us that we could visit and observe their classes in their respective class periods. The classes we were permitted to observe concerned 'Teaching Poetry' (Third Year B. A.) and 'ELT Methods and Practices' (Third Year B. Ed.). He also informed on our request that, according to the register books, there were respectively 23 and 28 students in B. A. and B. Ed. Third Year classes of English. Below are the outlines of the lessons.

Picture A: Third Year B. A. Classroom

Out of those 23 students recorded in the register book there were 11 in the classroom which was capable of holding 40-50 students in terms of the desks and benches. Among the absentees was Mr. J., too. The students were scattered mostly in pairs on the benches wherever they liked- from the front to the back. At the front of the class was a 'teacher's dais' with a wooden podium at its front part and a white board on the wall at the back. Notably, almost every student had a ball pen and a notebook with him/her. We sat at the back of the classroom and recorded and noted down the major activities in our diaries. Later on, we mixed our data to ensure their authenticity through verification.

\section{Faculty Activities}

The class started with a 'good morning' extended by the faculty (F1), which was responded to by 3-4 students. F1 then wrote that day's topic down on the board: 'Elements of poetry'. First, he defined poetry as 'a metrical composition in the form of artistic language' followed by his explanation of the key terms 'metrical composition' and 'artistic language'. It seemed as if the teacher wanted to prove how and why poetry was a 'metrical composition' and an 'artistic language'. Secondly, he moved to 'the elements of poetry' as he wrote it down on the board. One after the other, he wrote down and then explained the terms 'expressiveness', 'persuasion', 'musicality', 'playfulness' and 'word games'. In a nutshell, most of what F1 did throughout the class was defining, telling and explaining. Some other expressions that interrupted were parts of classroom language: "Why noise?", "What are you doing there?" "No side talks please", "Didn't you understand?", "Listen carefully, OK" and finally "This much today".

\section{Student Activities}

As F1 explained the concepts, most of the students were engaged noting down what the teacher said, sometimes getting the teacher to 'repeat once'. Some of them, especially the 'back benchers', were observed making side talks; one of them had a set of ear phones inserted in his ears, coming out of his pocket. It was also observed during the class that a few of the students were yawning as they were noting down F1's explanation.

\section{Picture B: Third Year B. Ed. Classroom}

The setting of the classroom was very similar to the one described in 'Picture A'. However, the number of students in the latter case was slightly larger: 22 students out of 28 recorded in the register book were present in the classroom and that they were sitting in the front rows of benches with the ones at the back unoccupied. The subject to be taught was "ELT Methods and Practices", a language teaching course. We sat on a bench at the back of the room and did our job in the same way as in 'Picture A'. The faculty and student activities are summarized separately below.

\section{Faculty Activities}

Having greeted a 'Good afternoon', the faculty (F2) announced that day's topic: 'Approaches to teacher development'. Like F1 (Picture A), he defined the key word 'approach' and stated that there are eight of such approaches. He wrote one; defined it and explained it for a few minutes. In this manner, he covered five of such approaches. Finally, there was a list of five words below the topic: 'workshops/seminars', 'self-monitoring', 'teacher support groups', 'keeping a teaching journal' and 'peer observation and peer coaching'. Finally, he summed up by saying that the remaining three would be 'discussed' the next day. Unlike F1 (Picture A), he did not (need to) use any regulatory classroom language.

\section{Student activities}

The student activities were not fundamentally different than those described in 'Picture A' but they noted down without making any 'noises' and 'side talks' as they listened to the teacher.

As it is evident from Picture A and Picture B, there are more similarities than differences between the B. A. and B. Ed. classes. The typical lesson patterns are explainable under 'lesson initiating', 'lesson teaching' and 'lesson closing'- patterns which greatly contrast with the well-established framework of a (language) lesson: 'pre-teaching', 'while-teaching' and 'post-teaching'. Figure 1 displays the procedural patterns drawn from the Pictures. 


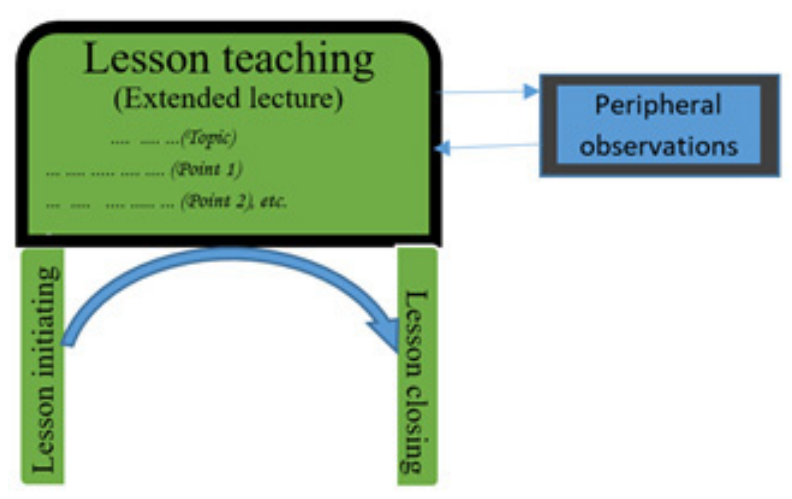

Figure 1. Procedural patterns in the excessive lecture-based ELT lesson

The so-called excessive lecture-based ELT class reveals three stages of teaching in the higher education ELT classroom: lesson initiating, lesson teaching and lesson closing (Figure 1). In this study, these stages were, to a large extent, common to both Pictures. As Case 2 portraits, the class commenced with a greeting initiated by the faculty, and responded to by [some of] the students (see Pictures A and B) often followed by a lesson declaration with the topic written simultaneously on the board (see Picture B). As part of lesson teaching (the second stage) the largest amount of time was spent by the faculty on lecturing as the delivery of the contents (see both Pictures). For this reason, we have named this pattern 'excessive lecture' (EL). As the faculty proceeded through his/her EL, he/she wrote down the sub-topics or the major points on the board. During the lecture, the faculty (F1) chiefly defined; explained or dictated the lesson orally; wrote down the points or sub-topics; repeated on students' request; consolidated the students' understanding and used classroom language of the regulatory kind (F1). The students were supposed to listen carefully; note down points/words or sentences uttered by the faculty and request repetitions as necessary. As part of the lesson closing stage, the faculty (F2) informed the students about the forthcoming lesson and took leave. Besides these, some peripheral observations such as side-talking and making irrelevant noise, dozing, yawning on the part of the students were also observed (Picture A). One of the scenes involved a few students with earphones inserted into their ears and sitting in a dispersed manner (classroom Picture A).

These typical patterns suggest that the teaching in these Cases was fully faculty-centered. The faculty's role was like that of a jug or a giver- pouring some liquid onto a mug, and the students were treated as the mug or receiver receiving the liquid. Thus, the teaching and learning processes in these situations were explainable as the 'jug-and-mug' style in which the faculty was 'spoon-feeding' the lesson to the students whereas the students were 'drinking' the lesson without special thirst. Differently, the students could be seen as passive listeners and the teacher more like a preacher.

\subsection{Triangulation: What the Faculties Thought}

It stands out that the Pictures of the classes we had observed and their precise descriptions given by Mr. J. and Mr. L. (Case 1) were essentially very similar. As the researchers, a further inquiry came to us: 'What made the faculties present their lessons in the way they did?' We immediately thought of an informal post-observation interaction with the faculties, who were somehow familiar colleagues with us. Accordingly, we invited them to tea at the canteen. We four sat at a separate table and initiated an informal interaction. First, we reported on what we had noticed and known about Mr. J., one of the students mentioned in Case 1, who stayed back in his room very often rather than attending his class at college regularly. From the F1, we sought some information about J's study and progress. He said that he was personally familiar with Mr. J, who according to him, was a 'genius' and one of the stipend winners based on his first year examination results, although he often missed the classes"That's a different matter, isn't it?" said he.

Then, as a strategy, we pulled the reference to their class presentations. We asked why they had followed EL, and not any other teaching strategies as appropriate. F1 responded, "That's what we can do in our situation, isn't it? There's no PowerPoint facility in our classrooms, you know". He added in a tone of a joke, "That's why we are lecturers!"

F2 knew that there were better alternatives to just lecturing but lecturing was the easiest as well as an in-fashion way of teaching in our context- "Let it be; who bothers!" he expressed. 
To our interest, an expression common to F2 and both of the students in Case 1 was "Who bothers!"

Yet, stemming from different perspectives, the common expression had different meanings for the students and one of the faculties. The students had expressed resignation whereas the faculty had expressed the lack of will-power (Figure 2).

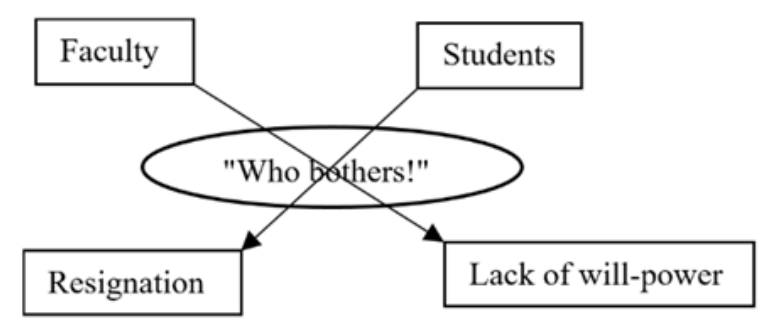

Figure 2. Faculty-students' cross-perspectives expressed with "Who bothers!"

Now, we logically confirmed that the students did not consider the classes worth attending [regularly] because the faculties did not find any meaning in teaching in a varied way as appropriate, or were not properly informed that there were several alternative ways, other than EL alone, that would suit their class presentations better.

\subsection{Suggested Alternatives}

Teachers can provide learners with better learning opportunities by the use of various teaching techniques and methods (Tawalbeh, 2018). Nonetheless, the methodology, including ELT, in the Nepalese higher education classroom, like at schools, is largely dominated by the excessive lecture method which, now we can argue, is not efficacious enough to catch the essence of learning. In harmony with the argument, the cases above do not match the core essence of learning. Nonetheless, school teachers and college faculties continually apply it to teaching [most of the subjects] or without knowing that there are some alternative strategies. On the other hand, students have developed a sort of frustration from it as in our Cases above. Arguably, the excessive lecture method has been one of the causes of the low quality of higher education in Nepal. For all these reasons, we would say, it is high time that the excessive lecture was kept to the minimum by supplementing it with some other teaching strategies as appropriate. With all these realities in mind, we present some alternative strategies (Table 1) which might be helpful in making higher education class presentations more effective and vivid.

Table 1. Suggested alternatives to the excessive lecture method (adapted from Wallace, 2010)

\begin{tabular}{lll}
\hline Recommended mode & Characteristic description & Example(s) \\
\hline BRAINSTORMING & $\begin{array}{l}\text { A group activity intended to generate a } \\
\text { lot of ideas. Participants at the beginning } \\
\text { are encouraged to think up ideas. Every } \\
\text { suggestion/idea is recoded. Decisions are }\end{array}$ & writing or literature)
\end{tabular}

BUZZ GROUPS Groups of students have a brief discussion (say, 5 minutes) to generate ideas or answer specific questions etc. Sometimes used as an activity during lectures.

CASE STUDY

COMPUTER

ASSISTTED

(LANGUAGE)
$\mathrm{CA}(\mathrm{L}) \mathrm{L}$ involves the use of specially designed computer programmes.
A group activity which uses the data gathered by a real 'case' or typical life situation.
Gathering some words/pronunciation variations/ expressions typically used in their locality to illustrate 'regional dialect' of the language (in a linguistics class)

(As part of practical work) Recalling and reporting (as a past event) a case in which someone misinterpreted a language function, and what happened as a result (in a language communication class)

(As part of home task) Listening to British and American accents of a set of words (in a linguistics class) 
LEARNING

CROSS-OVER

GROUPS

ELICITATION

DISTANCE

LEARNING

FEEDBACK

SESSION

FIELD STUDY

DRAMATIZATION

GAPPED LECTURE

GROUP WORK

GUIDED READING

INFORMAL

LECTURE

JIGSAW LEARNING
Different students cover different areas of a topic; they later pool their knowledge (e.g. by means of seminar papers)

The class is divided into groups which have a discussion. After some time, one or more members of each group move and the discussion continues. In this way, ideas from the different groups are shared without a need for a feedback session.

Also called SOCRETIC TECHNIQUE, it is a form of teaching by question-and-answer gradually leading to an inevitable truth.

(A system whereby) Students can have access to learning materials even when they are remote from the college, university, etc. which produced the materials. Students may be kept in touch by some means of information or communication.

1. Various individuals or groups report back to the class on what they have been doing as a task.

2. The teacher reports back to the students with an evaluation of their work (e.g. after an assignment has been corrected)

Students study phenomena at first hand.

Students dramatize, act it out in other words, what they have learned- a form of a game.

A kind of lecture which is interspersed with other types of activity, e.g. GROUP WORK.

Groups of learners are involved in working together- often distinguished from class work, in which the whole class works together.

Students are encouraged to read specific article(s) or section(s) of book(s) with a particular purpose in mind.

Informally delivered lecture in which audience reaction during the lecture is

welcomed.$$
\text { papers) }
$$
over and join one of the other groups,

Table 1 continued...

(As part of class work) Examining a text or a novel etc. in terms of some criteria (e.g. feminist criticism, organization of the material etc.) (in a literature or reading class)

(Toward the end of a discussion) Assessing a theory (e.g. the Mentalist view on language learning) to reach its advantages and drawbacks /limitations in a particular situation (in an ELT class).

(As part of home task)Visiting the web site of the college/university to do the $\operatorname{task}(\mathrm{s})$ individually or in a group, and presenting it/them in their 'session' when they meet at college, as in a session of one year B. Ed. (Distance Mode) under T. U. ( also see CA(L)L above )

(The teacher) Commenting on the students' preparation for writing compositions like a paragraph, an essay etc. (in a class of writing or literature), after a brainstorming session (see BRAINSTORMING above)

A real class observation to prepare a report for presentation (in an ELT class).

Changing a story into a dialogue + acting it out (in a reading/literature/language communication class)

Teacher tells how to present a microlesson, and the students are involved in planning it ( in an ELT class )

(A group of 'actors') Planning how to present/dramatize a story (in a reading/literature/language communication class) (also see GAPPED LECTURE).

(On the teacher's recommendation) Reading Mackey and Gass (2005, p. 7) to see how to write the abstract in a research report (in a research methodology class )

Raising cross-questions during the lecture (in a linguistics or literature class)

Making a research proposal combining together the headings prepared by different students (in a research methodology class ) 
Table 1 continued...

LECTURETTE

SELF HELP GROUP

OPEN LEARNING

PROJECT

PYRAMID GROUP

ROLE PLAY

SEMINAR

SIMULATION

TASK-BASED

LEARNING
A shorter-than-usual lecture (e. g. 15-20 mins.) given by the teacher, or sometimes, even by individual students.

A group of students who come together to help one another, outside the official teaching system.

(A system whereby) Students can have access to learning materials (usually, specially designed ones) at times which are convenient to themselves, in order to complete a program of study).

A task-based activity which usually involves an extended amount of independent work, either by an individual student or by a group of students.

Also called 'snowball group', in which the class is divided into groups. After some time, pairs of groups are joined together and continue the discussion. This is repeated until there is only one group, comprising the whole class.

(A form of simulation in which) The participants adopt certain roles or parts.

(Group activity in which ) One or more, and perhaps all, of the participants has/have to contribute something to the discussion usually in the form of a prepared paper or talk.

A group activity which pretends (simulates) situations, usually those which are likely to arise in one's real-life professional activities.

(Any kind of learning which involves) The performance of a specified task or piece of work.

Group activity usually led by a tutor. Tutorials may take a variety of forms, e. g. workshops, discussions, etc. Sometimes tutorials may be held on
Teacher gives a 'short talk' about 'postmodernism and literature' as a prelude to a group discussion, as an assessment.

Forming 'English speaking communities' for the practice of oral communication outside the classroom (in a language communication course)

Using the e-library of the college, which remains open all day for students involved in thesis/practicum writing (also see DISTANCE LEARNING above)

(Students in different groups) Doing a 'student-generated action research'(Beglar and Hunt, 2002, p. 97) into certain language functions of their choice in the local community ( from the introduction by the teacher to the formal presentation of their results/findings) (practical work in a language communication course)

(As a warm up) Teacher offers a number of choices to enjoy from- humor, song, acting, poem etc.-but only one this time. The students, first in groups and unanimously, say which one they'd choose, and why (in a language communication or literature class)

(As a post-reading performance) Playing the roles of the characters involved in a text that they have recently finished (in a literature/reading class)

(Students of Master's degree) Communicating individually their progress in writing the thesis, and facing queries raised by the team of teachers and fellow students

One student pretends to be a schoolboy and the other the principal of the school. The boy telephones his principal seeking confirmation if school runs tomorrow. (in a language communication class)

“...students working in small groups, choosing a topic of interest, and designing a questionnaire administer the questionnaire, analyze and interpret the data, and present their findings in class" (Beglar \& Hunt, 2002, p. 96 ) (in a research methodology class)

A tutor leading a micro-teaching session, training a small group (15) of student teachers on lesson planning (ELT) (in an on-campus pre-practice teaching session) 
one-to-one basis (i. e. one tutor, one student)

Table 1 continued...

\section{TUTORLESS} GROUP

WORKSHOP
(Virtually a kind of) Self-help group but officially recognized. It operates without the benefit of a tutor or teacher, who may, however, be available as a resource.

A task-based activity which involves the completion of a certain specified task ensuring that all the members of the group will contribute something to the completion of the task.
(Student teachers) Discussing, in their 'chamber', their teaching problem faced in a real ELT class (in the off-campus practice teaching field)

(Student teachers) Preparing flashcards (in an on-campus pre-practice teaching session )

As Poudel (2018) finds, most English teachers in Nepal see 'the environment' as an obstacle to effective ELT; so does F1 in the present study in some way, too. However, if the English language faculties in the higher education sector in Nepal wish, they can make their classroom presentations much better. One way of doing this is to plan their lessons in line with these strategies as appropriate and teach accordingly.

\section{Discussion}

In the present study, it was found that EL was applied most dominantly to teaching English in both FoH and FoE third year classes. Either EL was what F1 meant by teaching or he did not find any meaning in teaching in a varied and more effective way (F2) on the one hand, and for the same reason the students [in our case] did not consider the classes worth attending [regularly] on the other. Therefore, the findings significantly confirm to the views mentioned earlier (e. g. Kochhar, 1967; Brown, 1994; Law, 2012; UGC, 2008), and the empirically-based latest finding that the mismatch between teaching and learning styles causes failure and frustration among learners (Alnujaidi, 2019). Bello, Ibi, and Bukar's (2016) discussion also maintains that the lecture technique is ineffective because it makes only little impact on the academic performance of the learners who are passive and mere receipents of knowledge.

The stakeholders' claim that education in Nepal is 'theoretical' or 'impractical' seems to be in line wth the EUI report (2014) which suggests that the higher education graduates are not adequately employable. As it claims, the lack of adequate English langauge skills in the passed-out graduates is also likely to have some share with this. However, there is no evidence to support that the faculties in this study have developed the "Who bothers!" attitude because they are under-qualifiesd or under-paid. Rather, their beliefs can best be explained in relation to Mackay's (2015) argument that the way we were taught influences the way we teach.

The students' reasons for missing the classroom teaching were further justified by a methodological triangulation, i.e. class observation and the post-class informal interaction with the faculties. Similarly, the guardian's claim of 'impracticability' and 'non-employability' of 'our children's education' was justified by the result of this study. Likewise, the study findings are quite close to Law's (2012) observation that equating lecturing with teaching and learning is the biggest misconception prevailing in the institutions of [higher] education in Nepal. Notably, however, the patterns of EL as a language teaching method largely contradict with the key essence of the above as well as the current research findings on adult language learners, which emphasize collaboration between the speaker (teacher) and the listeners (students) for creating a productive learning environment (Ozfidan, Mahtmes, \& Demir, 2014). Interestingly, the lecture method integrated with group discussion, demonstration and experiment applied to changing the knowledge, attitudes and skills of food processors has proven effective in Rusnawaty and Heru's (2019) study. This suggests that the lecturette (Table 1) may be a better alternative EL.

As a case study, the study process was rather limited in terms of its space, participants, time and methods. First, it had stemmed from the problem statement related to the class absence of two students (one B. A. and the other B. Ed.) majoring in English at a college in a geographically peripheral area of Nepal with the primary data collected within two weeks' period. Two faculties (one teaching English to B. A. and the other to B. Ed.) from the same college were involved as the participants for the post-class interaction session. Second, as a methodological delimitation, the students who attended the classes were not involved as participants; nor were any opinions and views regarding the problem collected from those absent in the class and analyzed.

Assessing the limitations pointed out above, we can obtain some directions for similar studies in the future. For instance, if, as a methodological triangulation, the students who attended the classes and those who did not (other than the two whose cases were considered in this study) could be involved as participants for further information. 
Similarly, the participation of the other faculties, college administrators and staff could further enhance the study's reliability and validity. In other words, a larger scale research study is necessary to reach a more comprehensive conclusion.

\section{Conclusion (Note 3 )}

As the present study concludes, EL which prevails in ELT in the higher education sector of Nepal, is not suitable in terms of its efficacy for causing learning in learner(s). Although, in this mode of teaching, students are basically assumed to be careful and attentive listeners, rather than active participants, they grow to be passive learners. As a result, students not only are demotivated towards classroom learning but also develop a form of apathy to it to the extent that many of them stay back at home and read privately rather than regularly attending classes at college, a notion which we would call semi-drop-out.

Some of the college faculties teaching English fail to show their knowledge and acquaintance of the suitable alternative methods at the cost of EL. Yet, some of them claim to be well-acquainted with such alternatives but they are not very willing to apply them appropriately because they believe that it is an easy-to-use and 'in-fashion' method. In this sense, the latter category shows the lack of professional enthusiasm in them. In fact, the faculties seem to be conventionally used to equating teaching with EL.

The guardians and the experts' worries concerning the decreased quality of higher education in Nepal, of which particularly ELT is a part, are also consistent with the results of this study. Among others, one key factor causing the semi-drop-out among learners and the generally perceived low quality in higher education in Nepal is the use of EL as the unique strategy of teaching.

After all, as this study stands out, one challenging ailment of the ELT classroom in the higher education sector in Nepal is "Who bothers!" expressed by both of the classroom halves- the students and the faculty. Therefore, building on the results of the study, some recommendations can be put forth as a possible cure. First, it is high time that the excessive use of lectures in the higher education ELT classes was kept low by the use of the alternative strategies as appropriate (Table 1). This calls for the need for professional development programs for the faculties' attitude development/capacity building and refreshment to ensure the application of those strategies to teaching as appropriate. The concerned policy-level authorities need to take initiatives for this. Finally, a small but robust tip would be that the designation 'lecturer' awarded to the university faculties is irrelevant to their core assignment: 'learning director' (or any other?) would be a more suitable replacement.

\section{Acknowledgement}

The publication of this article was funded by University Grants Commission (UGC), Nepal. The authors are thankful to it as well as the anonymous reviewers without whose valued suggestions/feedback this article would not have come as such.

\section{References}

Alnujaidi, S. (2019). The difference between EFL students' preferred learning styles and EFL teachers' preferred teaching styles in Saudi Arabia. English Language Teaching, 12(1), 90-97. https://doi.org/10.5539/elt.v12n1p90

Beglar, D., \& Hunt, A. (2002). Implementing task-based language teaching. Methodology in language teaching: An anthology of current practice, 96-106. https://doi.org/10.1017/CBO9780511667190.015

Bello, S., Ibi, M. B., \& Bukar, I. B. (2016). Effect of simulation techniques and lecture method on students' academic performance in Mafoni Day Secondary School Maiduguri, Borno State, Nigeria. Journal of Education and Practice, 113-117.

Bista, K. (2011). Teaching English as a Foreign/Second Language in Nepal: Past and Present. English for Specific Purposes World, 11(32), 1-9.

Brown, S. D. (1994). Principles of language learning and teaching. Printice Hall Regents: Printice Hall, Inc.

Creswell, J. W. (2007). Qualitative inquiry and research design (2nd ed.). New Delhi: Sage Publications.

Crowe, S., Cresswell, K., Robertson, A., Huby, G., Avery, A., \& Sheikh, A. (2011). The case study approach. Medical Research Methodology, 1-9. https://doi.org/10.1186/1471-2288-11-100

Kochhar, S. K. (1967). Methods and techniques of teaching. New Delhi: Sterling.

Law, B. (2012). Expanding horizons in English: Teachers' manual. In B. Law, \& G. R. Gautam (Eds.), Kathmandu: NELTA. 
Loeng, S. (2018). Various ways of understanding the concept of andragogy. Congent Education, 5, 4-5. https://doi.org/10.1080/2331186X.2018.1496643

Mack, L. (2010). The philosophical underpinnings of educational research. Polyglossia, 19, 5-11.

Mackay, R. (2015). A basic introduction to English language teaching. New Delhi: Oxford University Press.

Miles, R. (2015). Complexity, representation and practice: Case study as method and methodology. Issues in Educational Research, 309-318.

Ozfidan, B., Mahtmes, K. L., \& Demir, H. (2014). Socio-cultural factors in second language learning: A case study of adventurous adult language learners. European Journal of Educational Research, 3(4), 185-191. https://doi.org/10.12973/eu-jer.3.4.185

Poudel, K. K. (2018). Transforming foreign language grammar classes through teacher training. World Journal of Education, 8(3), 86-99. https://doi.org/10.5430/wje.v8n1p86

Rahman, M. F., Babu, R., \& Ashrafuzzaman, M. (2011). Journal of NELTA, 16, 97-106. https://doi.org/10.3126/nelta.v16i1-2.6133

Rosen, M. (2010). Preface. In C. Tims (Ed.), Born creative (pp. 9-11). London: Demos.

Rusnawaty, U., \& Heru, S. I. (2019). Effectiveness of the use of demonstration and lecture method, group discussion and lecture method, and lecture method in food processing counselling at Karanganiyar district of Central Java, Indonesia. Russian Journal of Agricultural and Socio-Economic Sciences (RJOAS), 3(87), 166-174. https://doi.org/10.18551/rjoas.2019-03.20

Tawalbeh, T. I. (2018). EFL instructors' perceptions of blackboard learning management system (LMS) at university level. English Language Teaching, 11(1), 1-9. https://doi.org/10.5539/elt.v11n1p1

EIU (2014). High university enrolment, low graduate employment. Analysing the paradox in Afghanistan, Bangladesh, India, Nepal, Pakistan and Sri Lanka. An Economist Intelligence Unit report for the British Council.

Wallace, M. J. (2010). Training foreign language teachers: A reflective approach (1st ed.). New Delhi: Cambridge University Press.

\section{Notes}

Note 1. The words 'faculty' (pl. 'faculties') and 'Faculty' have been used to mean respectively college teacher(s) and a group of somehow similar departments under a university.

Note 2. Kamal Kumar Poudel (KKP), the principal author, envisaged the research design; conducted the preliminary case study; worked in collaboration with Netra Prasad Sharma (NPS), the corresponding author, and supervised the write up. NPS, collaborated with KKP in the research process from Case 2 onwards including the write up. Therefore, the personal pronouns 'I' ('me' 'my') refers to KKP and 'we' ('us', 'our') KKP and NPS both.

Note 3. Because the present case study design is underpinned by the instrumental type (see 'Study design'), the write up of this conclusion adopts an appreciation, i.e. has a generalized tone.

\section{Copyrights}

Copyright for this article is retained by the author(s), with first publication rights granted to the journal.

This is an open-access article distributed under the terms and conditions of the Creative Commons Attribution license (http://creativecommons.org/licenses/by/4.0/). 